\title{
Market Positioning of Branded Meat Products: A Case of the Feedlot Industry in South Africa
}

\author{
Prof. Hein Prinsloo \\ North-West University \\ E-mail: hein.prinsloo@nwu.ac.za \\ Anita Groenewald \\ Tshwane University of Technology \\ E-mail: groenewaldac@tut.ac.za \\ Prof. Theuns Pelser \\ North-West University \\ E-mail: theuns.pelser@nwu.ac.za
}

Doi:10.5901/mjss.2014.v5n1p129

\section{Abstract}

\begin{abstract}
Meat brand owners in South Africa, faces key challenges in positioning themselves in the mind of the consumer. The research problem centers on the fact that retail brand owners have to implement strategies of branding and positioning to maintain and enhance their competitiveness. This study explored the marketing efforts of meat producers in Middelburg, Mpumalanga, by drawing tangent planes between effective marketing and the knowledgeable consumer, and to determine if there is sufficient demand to ensure that the benefits of economies of scale are realised.The case study approach was used, and included quantitative and qualitative research. The population consisted of consumers buying meat products at the different retailers in Middelburg, Mpumalanga, under the brand names; Kanhym Fresh Meat, Farm Inn Meat and Frank's Meat. A sample of 612 was conveniently selected for the study. A total of 588 questionnaires were completed. The results of the study present a conceptual brand equity framework that represents and measures the influences that create brand equity for branded meat products. This conceptual framework makes a significant contribution to the market positioning of branded meat products.
\end{abstract}

Keywords: feedlot industry; branded meat products; branding; brand positioning; perceptual mapping;

\section{Introduction}

The South African consumer is privileged to be served with arguably the best beef in the world. The marketing challenges for the producers in the meat industry in South Africa are quite unique, and require a different perspective. Branding serves as a mechanism to solve some of these challenges. Branding is all about building assumptions, and although it is easy to provide a product with a suitable pleasing name, it is totally different to establish the philosophy and associated ethics supporting the trade mark in the minds of the consumers, convincing them that the brand is distinctively different from other brands (Bruwer, 2002).

Branded meat of consistently high quality, has earned a reputation worldwide as a means to increase beef consumption. The feedlot industry is the main beef producer in South Africa. For these meat retailers to be successful in an industry subjected to fierce competition, it is necessary to be innovative in a market where high quality beef serves as just another commodity (Prinsloo, 2006, p. 1).

\section{Literature Review}

This section looks at succesfull branding, branding attributes, as well as brand positioning.

\subsection{Successful branding}


According to Ries \& Ries (2003) there are four rules that must be considered when it comes to making a brand successful: First, one needs to get the brand to stand for something when the customer sees or thinks about it. When people start using a brand name generically, it means that that brand owns the category name. To become generic, one needs to be the first to sell something, and establish a category. Secondly, after successfully establishing the associations of this word, the brand owner decides whether to expand or contract the scope of its focus, so as to make more money. Although it seems logical to expand the scope to increase sales, this is a common mistake. As Ries and Ries (2003) explains:

\section{By far the most successful brands are those that kept a narrow focus and then expanded the category as opposed to those brands that tried to expand their names into other categories. (p. 46)}

The third and fourth aspects to consider when building a successful brand are quality and credentials. Quality exists in the mind of the customer, but it is only a perception. "There is almost no correlation between success in the marketplace and success in comparative testing of brands", claim Ries and Ries (2003 p. 58). Credentials are needed to claim authenticity or validity and have people believe almost anything being said by the brand owner about the performance of the brand. Having a high price is also a factor when building a perception of high quality in a brand. To a customer, a high price means good quality, even if this is not true. (Ries \& Ries: 2003).

For branding strategies to be successful and brand value to be created, consumers must be convinced that there are meaningful differences among brands in the specific product or service category. Brand differences are often related to attributes or benefits of the product itself. Gillette, 3M and others have been leaders in their product categories for decades, due in part, to continual innovation. Furthermore, brands like Gucci, Chanel, Louis Vuitton and others have become leaders in their product categories by understanding consumer motivation and desires and creating relevant and appealing images around their products (Kotler \& Keller, 2009). Successful brands are those which are the focus of a coherent blending of marketing resources, and represent valuable marketing assets. A successful brand delivers sustainable competitive advantage and invariably results in superior profitability and market performance (De Chernatony, McDonald and Wallace, 2011).

\subsection{Brand attributes}

Brand image reflects consumers' perceptions of a brand's characteristics and is evaluated by the associations they hold in their memory. The different types of brand associations can be grouped according to their level of abstraction, the amount of information held, whether they are product related or non-product related and whether they refer to attributes considered essential by consumers (De Chernatony et al., 2011).

Understanding brand meaning involves understanding the symbolism and associations that create brand image, the mental impression consumers construct for a product. The richness of the brand image determines the quality of the relationship and the strength of the associations and emotional connections that link a customer to a brand. Advertising researchers call this connection or association, brand linkage (Moriarty, Mitchell and Wells, 2009, p. 254).

Brand elements are those characteristics that identify and differentiate the brand. The fundamental role of brand elements is to contribute to the formation and development of consumer confidence and trust. Brand elements by themselves do not create trust. If the story conveyed by the brand elements is coherent, consumers would more likely be receptive and then more willing to trust, but trust comes only through positive experience (Ind and Bjerke, 2007, p. 122).

\subsection{Brand positioning}

The term positioning refers to placing in that part of the market where it will receive a favourable reception or response compared to competing products. As a matter of strategy, a product should be matched with that segment of the market in which it is in all probability most likely to succeed. The product should be positioned so that it stands apart from competing brands. Positioning tells what the product stands for, what it is, and how customers should evaluate it. Positioning is achieved by using marketing mix variables, especially design and communication. With some products, positioning can be achieved on the basis of tangible differences (e.g. product features); with many others, intangibles are used to differentiate and position products (Jain, 2000, p. 359).

Marketers often use positioning or perceptual maps to portray market positions visually. A perceptual map is a multidimensional graphic image depicting consumer perceptions. These maps assist marketers in developing focused marketing mixes or strategies. It also helps the manager to assess and consider the advantage of an organisation's 
marketing program (Cant, Strydom, and Jooste, 2004, p. 188).

\section{Problem Statement}

In researching the marketing approach to branded meat products, the assumption was made that the elements of the marketing mix, namely price, product and distribution, were already established. However, the majority of research on brand attributes has been done on large multinational brands and comparatively little research has been done on meat branding (Wong and Merrilees, 2005). The challenge meat producers face in building a strong meat brand name is to ensure that customers first and foremost, have a positive experience when the product is purchased, and that their marketing programs create the desired knowledge structures for the brand. The importance to establish a link between brand variables and consumers' perception regarding the importance of these variables are thus critical in the success of branded meat products.

\subsection{Aim and objectives}

The aim of the study was:

To build a practical applicable positioning map for branded meat products.

In order to achieve the aim, the following objectives were addressed:

- To formulate a theoretical contribution within the ambit of this study to not only have an academic application, but to also serve as a practical application in solving meat retailers marketing and product positioning challenges.

- To determine the marketing and positioning strategy of for branded meat products.

- To identify opportunities that will differentiate and position branded meat products that will create consumer equity and build a strong brand name.

\section{Research Methodology}

\subsection{Research method}

The research method used in this research was the case study, and included quantitative and qualitative research, which is descriptive, (where the objective was restricted to describing current practices) and explanatory (where existing theory was used to understand and explain what was happening) in nature. For the purpose of this study, exploratory research was used to obtain information about the consumer preferences on attributes for branded meat. The population relevant to this research consisted of consumers buying meat products at the different outlets in Middelburg, Mpumalanga, which include only those retail shops that sell branded meat products within the mentioned region, namely Kanhym Fresh Meat, Farm Inn Meat and Frank's Meat.

Within this population group the effort was to obtain a sample size that represents the chosen population. A sample of 612 was conveniently selected for the study. The sample size imitates and exceeds the recommendation by Hair, Black, Babin and Anderson (2010, p. 707-708) in that the number of respondents should be a ratio of 14 observations to each variable in order to perform factor analysis. When the 12 variables identified in 3 categories are multiplied by the suggested 14 observations, a sample of 504 is recommended. For this research paradigm the semistructured interview type was used, that generally starts with a few specific questions and then follows the individual's tangents of thought with interviewer probes.

This research classification is qualitative and the reasoning is inductive. This case study research focused on three (3) meat retailers in Middelburg, Mpumalanga, namely, Kanhym Fresh Meat; Farm Inn Meat; and Frank's Meat. The unit of analysis used in this study, is represented by these three (3) small business branded meat retailers, and their consumers.

In the initial phase of the research study, semi-structured interviews were done with the brand owners of the three identified retail outlets, Kanhym Fresh Meat, Farm Inn Meat and Frank's Meat. After establishing, inter alia, the brand variables as portrayed by the brand owners this was then used as scaled questions in a quantitative questionnaire. Respondents could then rate the indicated variables which were used as feedback during the perceptual positioning stage of the empirical study. The questionnaire was then first pilot-tested and afterwards, modifications were made to this data collection instrument to increase its ease of use. The final questionnaire was issued at the different retail outlets 
where consumers buy the branded meat products. A total of 588 questionnaires were completed of which 24 were not taken into consideration due to incomplete or inconclusive questionnaires.

\subsection{Ethical considerations}

All information gathered for this research was used for academic purposes only. Ethical approval for the study was obtained from the Chairperson of the Human Research Ethics Committee of the North-West University, Mafikeng Campus. Data collection was done in a manner that did not disrupt the lives of respondents; participation was voluntary, anonymous and confidential. Prior to any activity the respondents were informed about the nature and purpose of the study; they were also assured that they could withdraw at any given stage if they wished to.

\subsection{Reliability and validity}

Since factor analysis was used to validate the questionnaire in this study, reliability of the scale was required to ensure that the questionnaire reflects the construct it is measuring. It is for this reason that Cronbach alpha was used. The justification for using Cronbach coefficients was based on the general acceptability in the marketing literature for the use of this type of analysis (Hair et al., 2010, p. 118). Cronbach's alpha determines the internal consistency or average correlation of items in a survey instrument to gauge its reliability (Lund, 2012, p. 1). For this study, the minimum reliability coefficient is set at $a \geq 0.70$. However, in cases of lower reliability coefficients, a lower coefficient may be sufficient for analytical scrutiny. An acceptable minimum coefficient for attitudinal and behavioural constructs on ratio scales is 0.7 (Field, 2007, p. 668).

To examine the appropriateness of factor analysis in this research study, the Kaiser-Meyer-Olkin (KMO) measure of sampling adequacy was utilized. The KMO measure of sampling adequacy provides an index (between 0 and 1 ) of the proportion of variance among the variables that might be common variance. Values between 0.5 and 0.7 are mediocre and values between 0.7 and 0.8 are good, values between 0.8 and 0.9 are great and values above 0.9 are superb (Field, 2007 , p. 647). The KMO value for this research was $>0.8$, which is acceptable as a good value.

\section{Findings and discussion}

Cluster analysis on the variables using Ward's method on Euclidean distances yielded two main clusters (see Table 1). Internal consistency of the data was assessed by calculating Cronbach's alphas and in addition inter-tem correlations were calculated.

In question 1, the first cluster, named competence consisted of the following variables: competent staff, service, value added products, consistent quality, healthy wholesome products, quality products, variety of products and a clean store. This cluster groups the variables that consumers find important when they consider the process of delivering the meat to the consumer. The second cluster, named valuable consisted of the following variables: traceability, value for money, price and convenience. This cluster groups the variables that consumers find important to consider the value of the product.

Table 1. Reliability analysis

\begin{tabular}{|lcc|}
\hline \multicolumn{1}{|c}{ Construct } & Cronbach's alpha & Mean item correlation \\
\hline Question 1 - 'Competence' cluster & .86 & .42 \\
Question 1 - 'Valuable' cluster & .58 & .28 \\
Question 2 - 'Quality' cluster & .79 & .31 \\
Question 2 - Added product value' cluster & .75 & .43 \\
\hline
\end{tabular}

In question 2 the first cluster, named quality consisted of the following variables: packaging, tasty meat products, quality products, hygienic products, healthy wholesome organic products, good service, price and convenience. This cluster groups the variables that consumers find important when they consider the quality of a product. The second cluster in question 1, named added product value consisted of the following variables: traceable origin, marbled meat, unique customized product and added value. 
Using qualitative research (interviews with meat retail owners) - the important attributes consumers use when choosing between brands, were identified. In Figure 1 and Figure 2 the three brands were plotted on a two-dimensional map. From the data obtained it was possible to display in Figure 1 customer perceptions of their preferred brand with relation to 'Price', 'Value for money' 'Traceability' and 'Convenience' and Figure 2 is an illustration of customer perceptions of their preferred brand with relation to 'Quality' and 'Added product value'.

From Figure 1 it is evident that 'Competence' is the attribute that is rated the highest for all brands and 'Traceability' attribute has the lowest rating and measured average for all brands. The other three attributes 'Price', 'Convenience' and 'Value for money' differ slightly from one brand to another but the overall ratings are between 3.5 and 4.

In order to determine the different brands' position in relation to 'Quality' and 'Added product value', this research is used to illustrate the data with the use of a perceptual map as shown in Figure 2.

Furthermore, from Figure 2 it can be seen that the respondents rated 'Quality' as the most important brand attribute significantly more important than 'Added product value' for which average ratings were reported. It can be noted that respondents feel quite neutral about 'Added product value' as a brand attribute.

Figure 1. Brand comparison

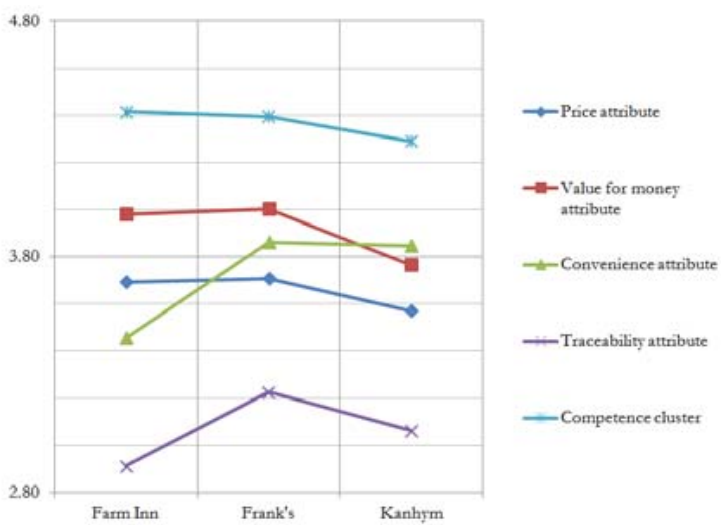

Figure 2. Consumer's assessment of attributes

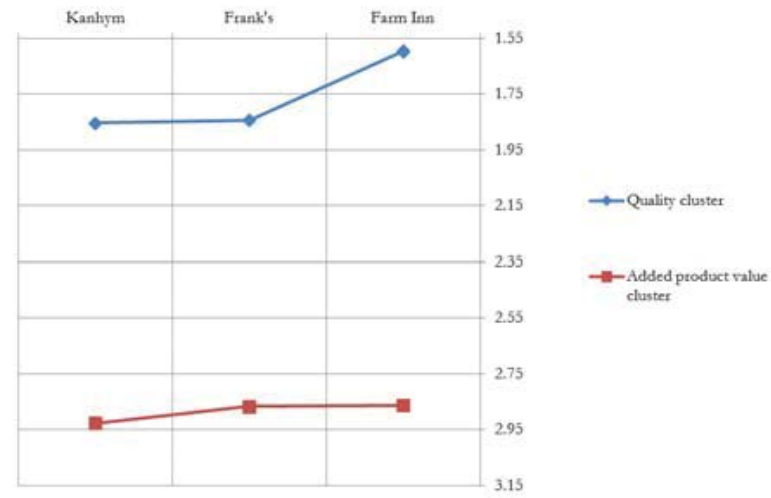

When the respondents were asked how can the various elements of the promotional mix be combined into an effective marketing program for branded meat products? $63 \%$ of respondents indicated that they are influenced by 'word of mouth' and the only other marketing influences worth mentioning are advertising in the local newspaper (15\%) and promotions presented by the retailer (14\%). Furthermore, when respondents were asked what type of communications they would prefer, they indicated by a large margin, (44\%) advertising in the local newspaper, followed by special events (29\%) and in-store promotions (19\%). 
The data from the research was used to build a positioning map for branded meat products in Middelburg, Mpumalanga as illustrated in Figure 3. The positioning map illustrate that consumers rated Farm Inn the highest on 'Quality' and 'Competence' of staff. Frank's Meat had the same high score for 'Competence' of staff as Farm Inn, but slightly lower ratings on 'Quality'. Although Kanhym Fresh Meat was also in the 'High' quadrant of the positioning map, it was the brand that scored the lowest on 'Quality' and 'Competence' of staff.

Figure 3. Positioning map for branded meat products

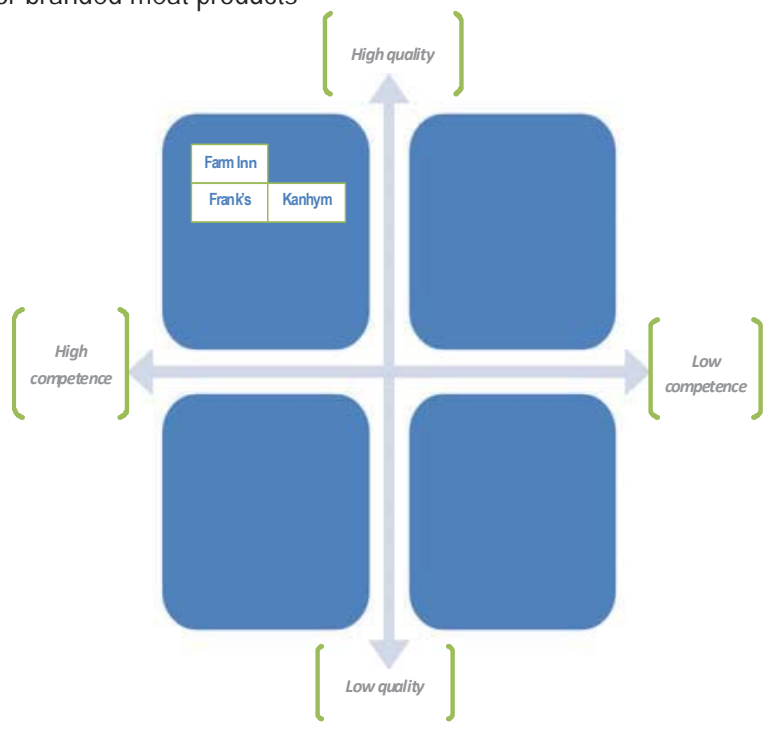

\section{Recommendations}

The following recommendations, if implemented can assist the meat retailers to develop a market brand positioning strategy and enhance their brands in becoming even stronger:

- Recommendation 1: It is important that the brand retail owner focus the marketing program on one or two key attributes. The brand retailer can further concentrate on attributes that makes its brand different from the competitors. Focus on these key associations and reinforce it across the marketing program over time.

- Recommendation 2: Due to the growing aversion to advertising, the increasing importance of channels such as 'word of mouth', Facebook and consumer blogs, is opening up an entirely new world of practical marketing possibilities for the successful marketers of the future. The meat retail owner must be able to design creative brand building push campaigns.

- Recommendation 3: Maximise the contribution of each brand attribute preference used to build brand equity. It is important to focus on the areas where respondents rated values indifferent, for example in this study attributes like 'marbeling', 'added product value' and 'traceablity' because it is in these areas that improvements can be affected to ensure a better understanding and building of a stronger meat brand.

- Recommendation 4: A meat retailer can leverage as many secondary associations as possible. Make use of any entity with potential relevant associations that can signal quality and credibility. The branded meat retail owners need to establish branding strategies that will focus on the brand's image, striving to occupy a distinct and valued place in the minds of its consumers and competitors by reinforcing the important attributes like 'quality' and 'competence' of the brand.

\section{Concluding Remarks}

Most research on brand attributes has been done on large multinational brands and comparatively little research has been done on meat branding (Wong \& Merrilees, 2005:157). This study sought to gain a better understanding of what role brand attributes play in the consumer's decision making process when buying branded meat. 
The analogy can be drawn from the research that the three branded meat products are all considered strong brands and the consumers seem content with their brand of choice. Branding is about being different and for a branded product to be considered superior it is necessary that brand meat retailers focus on the attributes that can make their product different and better than the competition. The results from the survey returned that although the attributes that constructs brand equity tested positively, the brand meat retailer should react on the indifferences found of the respondents, and which importance they attached to the different brand attributes.

The results of the study present a conceptual brand equity framework that represents and measures the influences that create brand equity for branded meat products. This conceptual framework makes a significant contribution to the market positioning of branded meat products.

\section{References}

Bruwer, G. (2002). Branding - The future of meat marketing? (Paper read at the launch of the new Tenderlicious branded beef function.) October 2002. Mpumalanga. (Unpublished).

Cant, M.C., Strydom, J.W. \& Jooste, C.J. (2004). Essentials of Marketing. $2^{\text {nd }}$ ed. Cape Town: Juta.

De Chernatony, L., McDonald, M. \& Wallace, E. (2011). Creating powerful brands. $4^{\text {th }}$ ed. Oxford: Butterworth-Heinemann.

Field, A. (2007). Discovering statistics using SPSS. $2^{\text {nd }}$ ed. London: Sage.

Hair, J.F. JNR, Black, W.C, Babin, B.J \& Anderson, R.E. (2010). Multivariate data analysis: a global perspective. $7^{\text {th }}$ ed. Upper Saddle River: Pearson Prentice Hall.

Ind, N. \& Bjerke, R. (2007). Branding governance: a participatory approach to the brand building process. West Sussex: Wiley.

Jain, S.C. (2000). Marketing Planning \& Strategy. $6^{\text {th }}$ ed. Cincinnati: South-Western.

Kotler, P. \& Keller, K.L. (2009). Marketing management. 13th ed. New Jersey: Pearson Prentice Hall.

Lund, A. (2012). Cronbach's Alpha (a) using SPSS. [Online]. Available from: https://statistics.laerd.com/spss-tutorials/cronbachs-alphausing-spss-statistics.php Date accessed 10 Nov 2012.

Moriarty, S.E., N. Mitchell \& Wells, W. (2009). Advertising principles and practice. $8^{\text {th }}$ ed. Upper Saddle River: Pearson Education.

Prinsloo, T.L. (2006). Kanhym lewer voortreflike vleis. Middelburg Observer, 3. 5 Oct.

Ries, A. \& Ries, L. (2003). The 22 immutable laws of branding. London: Profile Books.

Wong, H. Y. \& Merrilees, B. (2005). A brand orientation typology for SMEs: a case research approach. Journal of Product \& Brand Management, 14(3), 155-162. 
